\title{
Knowledge and Practice of Breast Self Examination for Early Detection of Breast Cancer Among Young Women Attending Maternal Health Clinic at JOOTRH, Kisumu County
}

Macxine Achieng Oguta ( $\nabla$ macxineoguta@gmail.com )

Kenya Medical Research Institute - Centre for Global Health Research (KEMRI-CGHR)

George Ayodo

Jaramogi Oginga Odinga University of Science and Technology

Felix Humwa

SJF Analytics

Shehu Shagari Awandu

Jaramogi Oginga Odinga University of Science and Technology

\section{Research Article}

Keywords: Breast Self-Examination, Breast Cancer, Practice, Knowledge

Posted Date: March 2nd, 2022

DOI: https://doi.org/10.21203/rs.3.rs-1359473/v1

License: (c) (i) This work is licensed under a Creative Commons Attribution 4.0 International License.

Read Full License 


\section{Abstract \\ Background}

Breast self-examination (BSE) is a simple, low-cost, and non-invasive method that women use to detect breast cancer at early stages. BSE is recommended for teenage and adult women as it helps to detect unusual swelling and lumps. The early intervention reduces the spread of cancer cells and improves health outcomes. This study assessed the knowledge and practices of BSE for early detection of breast cancer among women attending maternal health clinic at Jaramogi Oginga Teaching and Referral Hospital (JOOTRH), Kisumu County in Kenya.

\section{Methods}

A cross-sectional study targeting women of reproductive age seeking maternal health services at the JOOTRH facility was conducted. Systematic sampling was used to select the study participants while purposive sampling was used to select the nurses involved in key informant interviews. Semi-structured questionnaires and recording were used to collect data. Descriptive and logistic regression was conducted for the quantitative data. Qualitative data was transcribed, coded and analyzed thematically.

\section{Results}

The study found that $39 \%$ of the participants had the correct knowledge and practice of BSE. An increase in education level was significantly associated with correct knowledge and practice of BSE. Single participants $(\mathrm{aOR}=0.6,95 \% \mathrm{Cl}[0.36-0.99])$, participants who heard about $\mathrm{BSE}$ from media $(\mathrm{aOR}=0.51$, $95 \% \mathrm{Cl}[0.27-0.97])$ and friends $(\mathrm{aOR}=0.25,95 \% \mathrm{Cl}[0.09-0.69])$ were less likely to report correct knowledge and practice of BSE.

\section{Conclusion}

There needs to be concerted effort to raise the knowledge and practice of BSE by the national and county governments, stakeholders and health practitioners for the early detection of breast cancer.

\section{Background}

Cancer is a primary health concern in most regions of the world, and breast cancer, in particular, is a leading cause of cancer death among women in both developed and developing countries[1]. Breast cancer is not only the most diagnosed cancer in women, but also the leading cause of cancer death globally. It accounted for $24.2 \%$ of the 8.6 million new cases, and $15 \%$ of the 4.2 million deaths of cancer globally in 2018. Sub Saharan Africa accounted for $8.1 \%$ and $15 \%$ of new cases and deaths[2]. An estimated 7 out of 10 breast cancer patients in developing countries are likely to die from the condition as 
compared to only 2 out of 10 in developed countries[3]. According to the Kenya Ministry of Health, National Cancer Screening Guidelines [4] breast cancer accounts for $6.6 \%(626,679)$ of all cancer deaths, having an incidence of 2,088,849 cases. These projections of incidence and mortality in sub-Saharan Africa are worrying, hence the need to prevent and detect breast cancer early through various screening methods as a means of achieving the sustainable development goal (SDG) 3.4 by 2030.

Stage of disease at diagnosis is the most important prognostic variable and thus early diagnosis is a crucial alternative that should be prioritized in the management of breast cancer. Research conducted by [5] reported that most of the breast cancer patients are being diagnosed with advanced stages of cancer, leading to high mortality and reduced chances of survival and approximately $80 \%$ of reported breast cancer cases get diagnosed at a late stage (III or IV) which greatly hinders curative treatment and chances of survival. Thus, screening for early detection is an important aspect in the control of breast cancer as it increases the detection of breast cancer in its early stages and hence improve prognosis and reduce mortality[6-8]. However, it is essential to assess the efficacy of the screening method in minimizing disease burden and its affordability to the target populations [5]. For example, while mammography may be effective in high-resource setting, resource constrained areas may not be able to afford it and thus might opt for Breast Self-Examination (BSE) as it is cost-free, convenient, and easy to conduct.

Educating women about BSE helps them to be familiar with the anatomy of the breast and the normal condition of the breast, enabling them to identify any changes in the breast like abnormal swelling and lumps should they occur in the future. According to WHO [6], BSE is most effective when combined with Clinical Breast Examination (CBE) and mammography to detect the early signs of breast cancer. Review of breast self-examination techniques during gynecological and general hospital visits with health providers are among the most effective factors in promoting the use of breast self-examination. Additionally, the encouragement of the practice and education complement BSE practice [9].

Breast cancer is detected through three major ways: secretion of nipple discharge, changes in the feeling of breast and nipple, and change in breast appearance [10]. Even though the presence of lumps may not be an indication of a breast cancer, but when accompanied with unexplained shape and size of breasts, nipple retraction, nipple discharge, and redness on the skin, it might be an indication of breast malignancy [9]. The most common presentation of breast cancer is a lump (79.4\%), while breast pain accounts for $26.8 \%$ [9]. Creating awareness about breast cancer among clinicians and non-clinician informants helps in early detection and effective treatment and management of breast cancer [9].

According to [11], breast cancer incidence is relatively high in developing countries as compared to developed countries with the former diagnosing twice as many breast cases among women aged between 15 and 49 years. The research reports that in low-resource regions, 70\% of the newly diagnosed cancer patients are likely to die as compared to only $20 \%$ in high-resource locales. Data from National Screening Guideline shows that between 2014 and 2016, about $64 \%$ of cancer patients were diagnosed at stage III or IV in Kenyatta National Hospital according to Kenya Ministry of Health National Cancer 
Screening Guidelines [4]. During these later stages, it is difficult to achieve treatment for cure. Breast cancer awareness and surveillance in Kenya have been suboptimal and many women are not exposed to information that will promote awareness and early detection of this disease such as routine breast selfexaminations and the red flags to look for.

\section{Methods}

\section{Study aim, design and setting}

The study aimed to assess the knowledge and practice of breast self-examination for the early detection of breast cancer among young women. This cross-sectional study was conducted at the maternal clinic of Jaramogi Oginga Odinga Teaching and Referral Hospital (JOOTRH) in Kisumu County, Kenya. JOOTRH is a regional referral hospital in Western Kenya. Most of the residents in this community are peasant farmers and businesspersons, mainly dealing with fish products. The focus of this study was women within the reproductive age bracket.

\section{Study Participants and Data Collection}

The study participants constituted of the health facility nurses and women of aged 15-49 years attending an antenatal and maternal clinic at JOOTRH, Kisumu, Kenya. Data was collected through interviewing study participants using semi-structured questionnaires with both open and closed ended questions to answers research questions. Key informant interviews were used to interview the health care providers (nurses) in the maternal health clinic at JOOTRH

\section{Sampling}

The study used the sample size formula for a single population proportion [12] by using the prevalence of $41 \%$ taken from Mbagathi hospital in Nairobi, Kenya [13], level of significance at $5 \%$, margin of error at $5 \%$ and attrition rate of $10 \%$ leading to a sample size of 410 women. Five nurses who were working in the maternal section were purposefully selected to participate in the key informant interviews. Systematic sampling was used to select the study participants.

\section{Data Processing, Analysis and Presentation}

Data from the participants was cleaned and analyzed using $\mathrm{R}$ version 4 and qualitative data was transcribed, coded and analyzed thematically. Participant characteristics were presented in tabular and graphical form. Categorical variables were presented by use of frequencies and percentages while continuous variables were presented by use of median and interquartile range. Knowledge and practice of breast self-examination was coded in a binary form as the outcome. Prevalence of knowledge and practice of breast self-examination was presented by use of proportions. Knowledge and practice indicators were scored. Participants with a mean score of more than $80 \%$ for all indicators were coded as having substantial knowledge and practice. Bivariate logistic regression was used to determine factors associated with the study outcome. A priori of $p<0.2$ was used at the bivariate analysis to fit the 
variables to the multivariate logistic regression. The multivariate logistic regression identified independent determinants of knowledge and practice of breast self-examination. Associations were reported by use of odds ratios (OR) with their $95 \%$ confidence intervals $(\mathrm{Cl})$. Statistical significance was taken at $p<0.05$.

Qualitative data was collected from the nurses working in the maternal clinic by use of key informant interviews. Thematic content analysis was used to identify the broad themes on knowledge and practice of breast self-examination for the early detection of breast cancer among women seeking services at the maternal clinic. Analysis was done by use of NVivo 12 software.

\section{Results}

The study collected data from 398 of the 410 intended women of reproductive age attending maternal clinic at JOOTRH. Most of the participants were aged between $25-30$ years, 37.9\% (151/398), 31-35 years and $27.6 \%$ (110/398). Approximately half of the participants $50.75 \%(202 / 398)$ had primary education while slightly more than a quarter had secondary education $28.6 \%(114 / 398)$. Participants that were married were $38.7 \%(154 / 398)$ and never married were slightly less at $37.2 \%$ (148/398). More than half of the participants were in the semi-skilled manual labor at $55.8 \%(222 / 398)$ compared to less than a tenth who were unemployed $9.1 \%(36 / 198)$ Table 1. 
Table 1

Participant Characteristics

\begin{tabular}{|c|c|c|}
\hline Characteristics & $\mathbf{N}$ & $\%$ \\
\hline \multicolumn{3}{|l|}{ Age group } \\
\hline $18-24$ years & 85 & 21.36 \\
\hline $25-30$ years & 151 & 37.94 \\
\hline $31-35$ years & 110 & 27.64 \\
\hline $36-49$ years & 52 & 13.06 \\
\hline \multicolumn{3}{|l|}{ Education Level } \\
\hline None & 20 & 5.03 \\
\hline Primary & 202 & 50.75 \\
\hline Secondary & 114 & 28.64 \\
\hline College/higher & 62 & 15.58 \\
\hline \multicolumn{3}{|l|}{ Marital status } \\
\hline Married & 154 & 38.69 \\
\hline Single/Never married & 148 & 37.19 \\
\hline Separated/Divorced & 96 & 24.12 \\
\hline \multicolumn{3}{|l|}{ Occupation } \\
\hline Unemployed & 36 & 9.05 \\
\hline Semi-Skilled Manual & 222 & 55.78 \\
\hline Unskilled manual & 48 & 12.06 \\
\hline Agriculture & 38 & 9.55 \\
\hline Sale \& Service & 31 & 7.79 \\
\hline Clerical & 3 & 0.75 \\
\hline Professional technical/managerial & 14 & 3.52 \\
\hline Student & 6 & 1.51 \\
\hline \multicolumn{3}{|l|}{ Religion } \\
\hline Catholic & 136 & 34.17 \\
\hline Protestant & 150 & 37.69 \\
\hline Muslim & 8 & 2.01 \\
\hline
\end{tabular}




\begin{tabular}{|lll|}
\hline Characteristics & N & $\%$ \\
\hline Other & 104 & 26.13 \\
\hline
\end{tabular}

Almost all the study participants had at least heard of breast cancer $96.2 \%$ (383/398). Majority of the participants reported having heard of breast cancer from the media (radio and television) $57.0 \%$ (227/398), the friends, doctor/nurse 10.1\% (40/398) and relatives at 7.8\% (31/398) as shown in Fig. 1. More than half of the participants who ever heard of BSE in relation to breast cancer were of the opinion that BSE should be conducted weekly $54.6 \%$ (209/383) while only a paltry $6.3 \%(24 / 383)$ yearly. Majority of the participants were of the opinion that BSE should be performed in front of the mirror $53.3 \%$ $(204 / 383)$ and slightly more than half thought they were at a risk of having breast cancer $52.0 \%$ (207/383) (Table 2). 
Table 2

Knowledge of Breast Self-Examination

\begin{tabular}{|c|c|c|}
\hline Characteristics & $\mathbf{N}$ & $\%$ \\
\hline \multicolumn{3}{|c|}{ Ever heard of BSE and breast cancer } \\
\hline Yes & 383 & 96.23 \\
\hline No & 15 & 3.77 \\
\hline \multicolumn{3}{|l|}{ Where heard from } \\
\hline Internet & 54 & 13.57 \\
\hline Media (Radio \& TV) & 227 & 57.04 \\
\hline Friends & 40 & 10.05 \\
\hline Doctor/Nurse & 31 & 7.79 \\
\hline Relatives & 31 & 7.79 \\
\hline Never Heard & 15 & 3.76 \\
\hline \multicolumn{3}{|c|}{ How often should one conduct BSE } \\
\hline Not sure & 2 & 0.52 \\
\hline Weekly & 209 & 54.57 \\
\hline Monthly & 148 & 38.64 \\
\hline Yearly & 24 & 6.27 \\
\hline \multicolumn{3}{|c|}{ How should BSE be performed } \\
\hline Don't Know & 2 & 0.52 \\
\hline In front of mirror & 204 & 53.26 \\
\hline Lying on bed & 127 & 33.16 \\
\hline In the bathroom & 50 & 13.05 \\
\hline \multicolumn{3}{|c|}{ Do you think you are at risk of breast cancer } \\
\hline No & 191 & 47.99 \\
\hline Yes & 207 & 52.01 \\
\hline
\end{tabular}

Of the participants who ever heard of BSE, 42.3\% (162/383) reported of ever practicing BSE. Among those who practiced $93.2 \%$ (151/162) reported performing BSE once in a month. The study found that $96.2 \%$ (383/398) of their partners are aware of breast cancer and a further $62.7 \%(240 / 383)$ reported that their partners had knowledge of BSE. More than three-quarters of the participants reported they would be 
willing to train their partners on BSE 78.3\% (300/383). All the women reported that they would recommend BSE to other women while $87.0 \%$ (333/383) of the women reported that they would encourage other women to engage their partners on assisting them to perform BSE (Table 3). 
Table 3

Practices of Breast Self-Examination

\begin{tabular}{|c|c|c|}
\hline Characteristics & $\mathbf{n}$ & $\%$ \\
\hline \multicolumn{3}{|c|}{ Do you practice BSE } \\
\hline Yes & 162 & 42.30 \\
\hline No & 221 & 57.70 \\
\hline \multicolumn{3}{|c|}{ How often perform BSE } \\
\hline Once weekly & 3 & 1.85 \\
\hline Once monthly & 151 & 93.21 \\
\hline Once quarterly & 5 & 3.09 \\
\hline Once yearly & 3 & 1.85 \\
\hline \multicolumn{3}{|c|}{ Partner aware of breast cancer } \\
\hline Yes & 383 & 96.23 \\
\hline No & 15 & 3.77 \\
\hline \multicolumn{3}{|c|}{ Partner has knowledge about BSE } \\
\hline Yes & 240 & 62.66 \\
\hline No & 143 & 37.34 \\
\hline \multicolumn{3}{|c|}{ Are you able to train partner on BSE } \\
\hline Yes & 300 & 78.33 \\
\hline No & 83 & 21.67 \\
\hline \multicolumn{3}{|c|}{ Partner can assist on BSE } \\
\hline Yes & 137 & 35.31 \\
\hline No & 251 & 64.69 \\
\hline \multicolumn{3}{|c|}{ Partner helps perform BSE } \\
\hline Yes & 48 & 35.04 \\
\hline No & 89 & 64.96 \\
\hline \multicolumn{3}{|c|}{ Would like partner to help perform BSE } \\
\hline Yes & 205 & 81.67 \\
\hline No & 46 & 18.33 \\
\hline
\end{tabular}




\begin{tabular}{|lcl|}
\hline Characteristics & $\mathbf{n}$ & $\%$ \\
\hline Yes & 383 & 100.00 \\
\hline No & 0 & 0.00 \\
\hline Would advise other women to engage their & partners perform BSE \\
\hline Yes & 333 & 86.95 \\
No & 50 & 13.05 \\
\hline
\end{tabular}

On the Key Informant Interviews on male involvement in BSE, it was reported by some of the nurses that the cultural aspect acts as a challenge in their participation

"Very few men are involved in women health related services of their spouses including cancer screening services such as breast cancer and BSE education. In addition, men who take their wives to the hospital for maternal visits are always viewed as inferior by their fellow men." (KII, Female, 46)

"In this facility I have not seen very many men escort their wives for common maternal hospital visits such as child delivery or infant vaccination services let alone for cancer awareness". (KII, Male, 38)

Some of the KIls also gave the perceived benefits of male involvement as shown in the excerpts that follow

"Generally, if the man understands his role as the head of the home and cares for his family decision making on woman health-related matters will be prompt. This discussion creates awareness in the home on the needs of the woman to the spouse making the man more responsible" (KII, Female, 30)

"The man will be aware of the benefits of healthy maternal lifestyle leading to prompt detection diagnosis and treatment should there be need.". (KII, Female, 34)

About 39.4\% (151/383) of the interviewed participants who ever heard of Breast Cancer had the correct knowledge and practice of BSE. Participants who were aged $41-49$ years, $18(43.9 \%)$, of them had correct knowledge and practice of BSE. Fewer participants aged 18-24 years $24(28.2 \%)$ had the correct knowledge and practice of BSE. Among participants who had college/ higher education, $31(50.0 \%)$ of them had correct knowledge and practice of BSE. Almost half of the separated/divorced participants had the correct knowledge and practice of BSE. More of the results are as shown in Table 4. 
Table 4

Determinants of correct knowledge and practice of BSE among women seeking maternal health care at JOOTRH

\begin{tabular}{|c|c|c|c|c|c|}
\hline Characteristics & $\begin{array}{l}\text { Knowledge and } \\
\text { Practice (\%) }\end{array}$ & uOR (95\%Cl) & $\begin{array}{l}p \\
\text { value }\end{array}$ & $\begin{array}{l}\text { aOR } \\
(95 \% \mathrm{Cl})\end{array}$ & $\begin{array}{l}p \\
\text { value }\end{array}$ \\
\hline Age Group & & & 0.284 & & \\
\hline $18-24$ years & $24(28.24)$ & ref. & & & \\
\hline $25-30$ years & $62(41.06)$ & $\begin{array}{l}1.77(0.99- \\
3.14)\end{array}$ & 0.051 & & \\
\hline $31-35$ years & $42(38.18)$ & $\begin{array}{l}1.57(0.85- \\
2.89)\end{array}$ & 0.147 & & \\
\hline $36-40$ years & $18(43.90)$ & $\begin{array}{l}1.99(0.91- \\
4.33)\end{array}$ & 0.083 & & \\
\hline $41-49$ years & $5(45.45)$ & $\begin{array}{l}2.12(0.59- \\
7.60)\end{array}$ & 0.249 & & \\
\hline Education Level & & & 0.0794 & & \\
\hline None & $6(30.00)$ & ref. & & & \\
\hline Primary & 67(33.17) & $\begin{array}{l}1.16(0.43- \\
3.15)\end{array}$ & 0.774 & $\begin{array}{l}1.67(0.59- \\
4.73)\end{array}$ & 0.333 \\
\hline Secondary & $47(41.23)$ & $\begin{array}{l}1.64(0.59- \\
4.57)\end{array}$ & 0.347 & $\begin{array}{l}2.23(0.77- \\
6.50)\end{array}$ & 0.141 \\
\hline College/higher & $31(50.00)$ & $\begin{array}{l}2.33(0.79- \\
6.86)\end{array}$ & 0.123 & $\begin{array}{l}3.25(1.03- \\
10.25)\end{array}$ & 0.044 \\
\hline Marital status & & & 0.0063 & & \\
\hline Married/Cohabiting & $61(39.61)$ & ref. & & & \\
\hline Single/Never married & 43(29.05) & $\begin{array}{l}0.62(0.39- \\
1.01)\end{array}$ & 0.054 & $\begin{array}{l}0.60(0.36- \\
0.99)\end{array}$ & 0.048 \\
\hline Separated/Divorced & $47(48.96)$ & $\begin{array}{l}1.46(0.87- \\
2.45)\end{array}$ & 0.147 & $\begin{array}{l}1.07(0.61- \\
1.88)\end{array}$ & 0.808 \\
\hline Occupation & & & 0.1282 & & \\
\hline Unemployed & $16(44.44)$ & ref. & & & \\
\hline Agriculture & 87(39.19) & $\begin{array}{l}0.81(0.40- \\
1.64)\end{array}$ & 0.551 & & \\
\hline Unskilled manual & 16(33.33) & $\begin{array}{l}0.63(0.26- \\
1.52)\end{array}$ & 0.301 & & \\
\hline Semi-Skilled Manual & $8(21.05)$ & $\begin{array}{l}0.33(0.34- \\
2.38)\end{array}$ & 0.035 & & \\
\hline
\end{tabular}




\begin{tabular}{|c|c|c|c|c|c|}
\hline Characteristics & $\begin{array}{l}\text { Knowledge and } \\
\text { Practice (\%) }\end{array}$ & UOR (95\%Cl) & $\begin{array}{l}p \\
\text { value }\end{array}$ & $\begin{array}{l}\text { aOR } \\
(95 \% \mathrm{Cl})\end{array}$ & $\begin{array}{l}p \\
\text { value }\end{array}$ \\
\hline Sale \& Service & $13(41.94)$ & $\begin{array}{l}0.90(0.34- \\
2.38)\end{array}$ & 0.836 & & \\
\hline Clerical & $3(100.00)$ & - & & & \\
\hline $\begin{array}{l}\text { Professional } \\
\text { technical/managerial }\end{array}$ & $8(57.14)$ & $\begin{array}{l}1.67(0.48- \\
5.79)\end{array}$ & 0.422 & & \\
\hline Student & $0(0.00)$ & - & & & \\
\hline Religion & & & 0.9967 & & \\
\hline Catholic & $53(38.97)$ & ref. & & & \\
\hline Protestant & $58(38.67)$ & $\begin{array}{l}0.98(0.61- \\
1.59)\end{array}$ & 0.958 & & \\
\hline Muslim & $0(0.00)$ & - & - & & \\
\hline Other & $40(38.46)$ & $\begin{array}{l}0.98(0.58- \\
1.65)\end{array}$ & 0.936 & & \\
\hline \multicolumn{6}{|c|}{ Partner Knows about BSE } \\
\hline Yes & 150(39.16) & ref. & 0.035 & & \\
\hline No & $1(6.67)$ & $\begin{array}{l}0.11(0.01- \\
0.85)\end{array}$ & & $\begin{array}{l}0.08(0.01- \\
0.76)\end{array}$ & 0.028 \\
\hline \multicolumn{2}{|c|}{ How often should one perform BSE } & & 0.0304 & & \\
\hline Not sure & $1(50.00)$ & ref. & & & \\
\hline Weekly & $67(31.31)$ & $\begin{array}{l}0.46(0.03- \\
7.40)\end{array}$ & 0.581 & $\begin{array}{l}0.10(0.00- \\
4.55)\end{array}$ & 0.24 \\
\hline Monthly & $71(46.41)$ & $\begin{array}{l}0.87(0.05- \\
14.10)\end{array}$ & 0.919 & $\begin{array}{l}0.18(0.00- \\
7.87)\end{array}$ & 0.372 \\
\hline Yearly & 12(41.38) & $\begin{array}{l}0.71(0.04- \\
12.43)\end{array}$ & 0.812 & $\begin{array}{l}0.14(0.00- \\
6.46)\end{array}$ & 0.312 \\
\hline Where heard from & & & 0.045 & & \\
\hline Internet & $29(53.70)$ & ref. & & & \\
\hline Media (Radio \& TV) & $84(37.00)$ & $\begin{array}{l}0.51(0.28- \\
0.92)\end{array}$ & 0.026 & $\begin{array}{l}0.51(0.27- \\
0.97)\end{array}$ & 0.039 \\
\hline Friends & $7(17.50)$ & $\begin{array}{l}0.18(0.07- \\
0.48)\end{array}$ & 0.001 & $\begin{array}{l}0.25(0.09- \\
0.69)\end{array}$ & 0.007 \\
\hline Nurse/Doctor & $10(32.26)$ & $\begin{array}{l}0.41(0.16- \\
1.03)\end{array}$ & 0.059 & $\begin{array}{l}0.45(0.17- \\
1.21)\end{array}$ & 0.115 \\
\hline
\end{tabular}




\begin{tabular}{|llllll|}
\hline Characteristics & $\begin{array}{l}\text { Knowledge and } \\
\text { Practice (\%) }\end{array}$ & uOR (95\%Cl) & $\begin{array}{l}\boldsymbol{p} \\
\text { value }\end{array}$ & $\begin{array}{l}\text { aOR } \\
(95 \% \mathrm{Cl})\end{array}$ & $\begin{array}{l}\boldsymbol{p} \\
\text { value }\end{array}$ \\
\hline Relatives & $14(40.00)$ & $\begin{array}{l}0.57(0.24- \\
1.36)\end{array}$ & 0.208 & $\begin{array}{l}0.61(0.25- \\
1.50)\end{array}$ & 0.281 \\
\hline Never Heard & $7(63.64)$ & $\begin{array}{l}1.51(0.40- \\
\text { 5.76) }\end{array}$ & 0.548 & $\begin{array}{l}1.65(0.39- \\
7.02)\end{array}$ & 0.495 \\
\hline
\end{tabular}

The study also found that participants with college education were more likely to report correct knowledge and practice of BSE (adjusted Odds Ratio [aOR] = 3.25, 95\% $\mathrm{Cl}$ [1.03-10.25], $\mathrm{p}=0.044$ ) compared to those with no education. In addition, those with primary and secondary education were also more likely to report correct knowledge on $\mathrm{BSE}(\mathrm{aOR}=1.67,95 \% \mathrm{Cl}[0.59-4.73], \mathrm{p}=0.333)$ and $(\mathrm{aOR}=$ $2.23,95 \% \mathrm{Cl}[0.77-6.50], \mathrm{p}=0.141)$ respectively than participants with no education, but it was not statistically significant. Participants who were not married/cohabiting were less likely to report correct knowledge and practice of $\mathrm{BSE}(\mathrm{aOR}=0.60,95 \% \mathrm{Cl}[0.36-0.99], \mathrm{p}=0.048)$ compared to the married/cohabiting. Lastly, participants who heard about BSE from media (aOR $=0.51,95 \% \mathrm{Cl}[0.27-$ $0.97], p=0.039)$ and friends $(a O R=0.25,95 \% \mathrm{Cl}[0.09-0.69], p=0.007)$ were less likely to report correct knowledge and practice than those who got the information from the internet (Table 4).

\section{Discussion}

This study found that a majority of its respondents both women and their partners were aware of breast cancer. Studies that have examined the attitudes and knowledge towards BSE have evidenced that improved breast cancer awareness has significant impacts on early detection practices [14]. In this study, the proportion of women with good knowledge of BSE was close to $40 \%$. This finding is comparable to studies done in Ethiopia, Eritrea and Nepal that ranged from 27-40\% [15]. However, the proportion of knowledge in this study is lower than what was reported in Saudi Arabia 79\%, Uganda, 76.5\%, Egypt $63.4 \%$ and Nigeria 55.4\% [15]. The differences in knowledge levels can be attributed to the varying socioeconomic and demographic characteristics among the study population.

Our study findings showed that majority of the participants had heard of BSE from the media and is in line with previous studies [16]; [17]. These studies have shown the need to increase knowledge of breast cancer and BSE through the use of media and healthcare providers. The role of healthcare providers has been mentioned severally as they educate and manage health diseases and detection such as breast cancer [18]. Some of the study participants had heard of BSE from friends and it has been evidence that discussion on health issues is anticipated to foster awareness on the subject matter of interest [15]. A study conducted in Kenya recommended the need to increase BSE coverage in the media [19]. It has been shown that health promotion programs on BSE increases the practice of BSE among women as it will increase their confidence thus leading to regular self-examination [20]. Studies have documented that women with adequate knowledge on breast cancer are more likely to regularly practice BSE [18]. 
In this study, it was observed that BSE is infrequent as less than half of the participants reported practicing BSE. Only $37 \%$ of the participants performed with the recommended periodicity of health institutions. A study done in Mexico reported 35\% of women carrying out BSE as per the health institutions recommendations [21]. Similar findings were observed in a study carried out in Ethiopia that reported $41 \%$ of women reported practicing BSE and only $18 \%$ knew the recommend frequency [22]. A study conducted in Cameroon on women reported in 120 women reported that $60 \%$ did BSE but only $35 \%$ performed it monthly [23]

This study found that almost all of the participants' male partners were aware of breast cancer, however only close to a third knew how to perform BSE. Similar findings were observed by [17] where it was revealed that even though $98.8 \%$ of the male participants were aware of breast cancer, they had limited knowledge about the disease.

The KIls revealed that most of the males do not think that it is culturally appropriate to accompany their wives to maternal health care visits and consider themselves dominated by their wives. The study finding are similar to a study by conducted in sub Saharan Africa that showed that men reported that they would be regarded as being 'ruled' by their wives if they were seen participating in maternal health care services [24]

The study's prevalence of BSE practice was almost similar to a study done on Indonesian women which found that $39.5 \%$ of the participants reported practicing BSE [25]. Almost similar finding were found in a study done in Tanzania, 33\%, and Ethiopia at 37\% [26] and [27].

Studies have shown statistical significance difference between socio-demographic characteristics and the knowledge and practice of BSE. This study found that women with higher level of education were more likely to practice BSE compared to those with little or no education. A study on Malaysian women found a positive association between the level of education and practice of BSE [18] Similarly, the findings corroborate results from an Ethiopian study that reported higher levels of education to be significantly associated to BSE [28]. Higher education increases BSE practice in detecting any difference in their breast due to adequate knowledge to perform BSE [21].

Married women were more likely to have the correct knowledge and practice and BSE as reported in this study. This finding is in line with previous studies that suggested that married women were more conscious of their breasts and were more likely to perform BSE [16]. In addition, the study found that participants who reported that their partners knew of BSE were more likely to report correct knowledge and practice. It has been evidenced that spousal emotional and economic support is key to a woman's confidence in seeking early treatment [18]. Despite the majority of the participants had heard of BSE from the media and their friends, they had less likelihood of practicing BSE than those who heard about it from the internet. This contradicts other studies that found that respondents who discussed with others on BSE were more likely to regularly practice it [15]. This discrepancy can be due to the difference in population as the study was conducted among university students who form a homogenous cohort compared to our study done in the general population. 
This study found no statistically significant association between age and BSE. A study conducted in Cuba on 80 women found that older women $>40$ years had greater knowledge and adherence to BSE practice though no statistically significant difference was observed and this is similar to the study findings[29]. However, previous studies done in Asia indicated that women with lower socio-economic status and women above 50 were less likely to perform BSE [18]. Studies done in Mexico and Ethiopia found that women who self-explored the most were aged between 20-29 years [30]; [21].

\section{Conclusions And Recommendation}

The study found that marriage and source of information as key factors that influence BSE. Participants who were married were more likely to have correct knowledge and practice of BSE compared to those who were not. Participants who got their source of information from the media and through friends were less likely to practice BSE than those who got the information from the internet.

The County together with the Ministry of Health should take steps to raise awareness on the importance and benefits of BSE in maternal health care services. They should also stress on the need for the correct practice of BSE. During routine hospital visits women should be educated on BSE; when and how to perform it and encouraged to report to a health facility in case any abnormality is detected.

\section{Limitations}

The study did not do a comparison of responses from the women who did not seek maternal services at the facility. However, this will not hinder the results of the study as most of the women access the free maternity services offered at the facility. Another limitation of the study was the impact of COVID - 19 pandemic on data collection. The study ensured that all the ministry of health COVID-19 containment protocols was strictly adhered to during the data collection. The research assistants were tested for COVID-19 on a biweekly basis and provided with Personal Protective Equipment kits. The participants were only allowed in with a mask and after washing their hands with soap that was provided by the facility.

\section{Abbreviations}

BSE - Breast Self-Examination

CBE- Clinical Breast Examination

J0OTRH-Jaramogi Oginga Odinga Teaching and Referral Hospital

JOOUST- Jaramogi Oginga Odinga University of Science and Technology

NACOSTI- National Commission for Science, Technology and Innovation

IERC-Internal Ethical Review Committee

Page $16 / 20$ 


\section{Declarations}

\section{Ethical Considerations}

Authorization to conduct this study was obtained from board of post graduate studies of Jaramogi Oginga Odinga University of Science and Technology (JOOUST). Permission to conduct the study was given from the County Health Management Team (CHMT) of Jaramogi Oginga Odinga Teaching and Referral Hospital (JOOTRH).All methods of the study were performed in accordance with all the relevant guidelines and regulations of the research and ethical committee of JOOTRH (Approval number IERC/JOOTRH/370/20). Additionally, permission was also obtained from the National Commission for Science, Technology and Innovation (NACOSTI) for the collection of information (Ref No:835921). An informed consent of the research participants was obtained before collecting the data. For the illiterate participants, informed consent from their parent or legal guardian was obtained and an impartial witness present during the informed consent process also signed and datedthe form. The collected data was deidentified and anonymised, and the information collected was only used by the researcher to ensure privacy and confidentiality of the participants' data.

\section{Consent for publication}

Not applicable

\section{Availability of data and materials}

All data generated or analysed during this study are included in this published article [and its supplementary information files].

\section{Competing interest}

The authors declare that they have no competing interest.

\section{Funding}

The study was self-funded.

\section{Authors' Contributions}

MAO designed, collected and authored the manuscript, SSA and GA assisted in the design, authorship, analysis and interpretation of the results, and HF did the cleaning and statistical analysis. All authors critically reviewed and revised the manuscript. 


\section{Acknowledgements}

The authors are grateful to the County director of health, the County public health officer, the chief and assistant chief of Kisumu County who permitted the study to be conducted in their area of jurisdiction. The authors are also grateful to the study participants and the research assistants who conducted the study diligently.

\section{References}

1. Medford, A.J., R.N. Gillani, and B.H. Park, Detection of Cancer DNA in Early Stage and Metastatic Breast Cancer Patients. Methods Mol Biol, 2018. 1768: p. 209-227.

2. Bray, F., et al., Global cancer statistics 2018: GLOBOCAN estimates of incidence and mortality worldwide for 36 cancers in 185 countries. CA Cancer J Clin., 2018: p. 394-424.

3. Birhane, K., et al., Practices of Breast Self-Examination and Associated Factors among Female Debre Berhan University Students. Int J Breast Cancer, 2017.

4. Health, K.M.o., National Cancer Screenig Guidelines. 2018: Nairobi.

5. Busakhala, N.W., et al., Screening by Clinical Breast Examination in Western Kenya: Who Comes? J Glob Oncol, 2016. 2(3): p. 114-122.

6. WHO. WHO fact sheet N297, 2013.

7. Hajian-Tilaki, K. and S. Auladi, (2014). Health belief model and practice of breast self-examination and breast cancer screening in Iranian women. . Breast Cancer, 2014. 21(4): p. 429-434.

8. Coleman, C., Early Detection and Screening for Breast Cancer. . 2017. 33(2): p. 141-155.

9. Makau-Barasa, L.K., et al., Improving Access to Cancer Testing and Treatment in Kenya. J Glob Oncol, 2018. 4: p. 1-8.

10. Sayed, S., et al., Breast cancer diagnosis in a resource poor environment through a collaborative multidisciplinary approach: the Kenyan experience. J Clin Pathol, 2013. 66(4): p. 307-11.

11. Birhane, K., et al., Practices of Breast Self-Examination and Associated Factors among Female Debre Berhan University Students. Int J Breast Cancer, 2017. 2017: p. 8026297.

12. Charan, J. and T. Biswas, How to calculate sample size for different study designs in medical research? Indian J Psychol Med, 2013. 35(2): p. 121-6.

13. Wambui, E.,, Breast self-examination practice for early detection of breast cancer among women of reproductive age seeking family planning services at Mbagathi Services at Mbagathi District Hospital, Nairobi, Kenya: http://erepository.uonbi.ac.ke:8080/xm/ui/handle/123456789/8303. 2012.

14. Sayed, S., et al., Breast Cancer knowledge, perceptions and practices in a rural Community in Coastal Kenya. BMC Public Health, 2019. 19(1): p. 180.

15. Mihret, M.S., et al., Knowledge and Practice on Breast Self-Examination and Associated Factors among Summer Class Social Science Undergraduate Female Students in the University of Gondar, Northwest Ethiopia. J Cancer Epidemiol, 2021. 2021: p. 8162047. 
16. Al Dubai, S.A., et al., Awareness and knowledge of oral cancer among university students in Malaysia. Asian Pac J Cancer Prev, 2012. 13(1): p. 165-8.

17. Ameade, E.P., et al., Reducing the breast cancer menace: the role of the male partner in Ghana. Asian Pac J Cancer Prev, 2014. 15(19): p. 8115-9.

18. Moey, S.F., N.C. Mohamed, and B.C. Lim, A path analytic model of health beliefs on the behavioral adoption of breast self-examination. AIMS Public Health, 2021. 8(1): p. 15-31.

19. Kanyeria, K.W., Breast Cancer Coverage In Kenyan Newspapers: Investigating A Prevention Agenda. 2017.

20. Sayed, S., et al., Breast Camps for Awareness and Early Diagnosis of Breast Cancer in Countries With Limited Resources: A Multidisciplinary Model From Kenya. Oncologist, 2016. 21(9): p. 1138-48.

21. Valderrama-Urreta, A.L., M.V. Jiménez-Báez, and J.C.E. Rodríguez, Social and demographics factors associated with the breast self-examination (BSE) in women in primary care. J Fam Med Dis Prev., 2018. 4: p. 1-6.

22. Lemlem, S.B., et al., Assessment of Knowledge of Breast Cancer and Screening Methods among Nurses in University Hospitals in Addis Ababa, Ethiopia, 2011. ISRN Oncol, 2013. 2013: p. 470981.

23. Suh, M.A., et al., Breast self-examination and breast cancer awareness in women in developing countries: a survey of women in Buea, Cameroon. BMC Res Notes, 2012. 5: p. 627.

24. Ditekemena, J., et al., Determinants of male involvement in maternal and child health services in subSaharan Africa: a review. Reprod Health, 2012. 9: p. 32.

25. Muhlisoh, D. Irawati, and T. Herawati, Association between cancer stigma and breast self examination among nurses. Enferm Clin, 2020. 30 Suppl 7: p. 60-64.

26. Azage, M., G. Abeje, and A. Mekonnen, Assessment of Factors Associated with Breast SelfExamination among Health Extension Workers in West Gojjam Zone, Northwest Ethiopia. Int J Breast Cancer, 2013. 2013: p. 814395.

27. Morse, E.P., et al., Breast Cancer Knowledge, Beliefs, and Screening Practices among Women Seeking Care at District Hospitals in Dar es Salaam, Tanzania. Breast Cancer (Auckl), 2014. 8: p. 73-9.

28. Legesse, B. and T. Gedif, Knowledge on breast cancer and its prevention among women household heads in northern Ethiopia. 2014;4(1):32-40. Open J Prev Med., 2014. 4(1): p. 32-40.

29. Li, Y., et al., Patient Perception and Cost-Effectiveness of a Patient Navigation Program to Improve Breast Cancer Screening for Hispanic Women. Health Equity, 2019. 3(1): p. 280-286.

30. Hailu, D. and H. Berhe, Determinants of institutional childbirth service utilisation among women of childbearing age in urban and rural areas of Tsegedie district, Ethiopia. Midwifery, 2014. 30(11): p. 1109-17.

\section{Figures}


A

Ever heard of Breast Self Examination or Breast Cancer

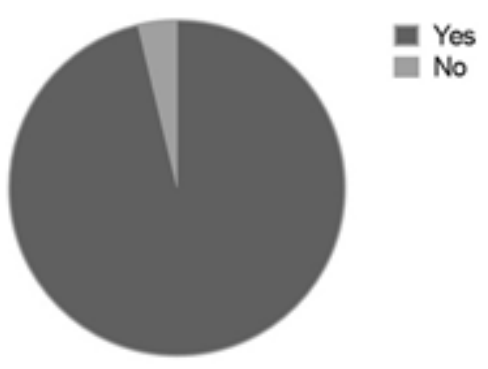

\section{Figure 1}

A) Heard of BSE and breast cancer; B) Place heard of BSE

\section{Supplementary Files}

This is a list of supplementary files associated with this preprint. Click to download.

- MacxineThesisrawdata.xlsx 